\title{
Identifying Older People at Risk of Abuse During Routine Screening Practices
}

\author{
Lisa R. Shugarman, PhD, * Brant E. Fries, PhD, ${ }^{\ddagger \neq}$ Rosalie S. Wolf, PhD, $\$ / \| \#$ \\ and John N. Morris, PhD"l
}

OBJECTIVES: To examine the association between various characteristics of community-based older people and a constructed measure of potential elder abuse.

DESIGN: Cross-sectional design.

SETTING: Public community-based long-term care programs in Michigan.

PARTICIPANTS: Individuals aged 60 and older seeking home and community-based services in Michigan between November 1996 and October 1997 ( $\mathrm{N}=701$ ).

MEASUREMENTS: Data were collected using the Minimum Data Set for Home Care (MDS-HC) assessment. The dependent variable is a constructed measure of potential elder abuse reflecting physical and emotional abuse and neglect. Independent variables include demographic characteristics; diagnoses; behavioral measures; and cognitive, physical, and social functioning.

RESULTS: Several measures of social support and social function were strongly associated with the signs of a potentially abusive environment: brittle support (odds ratio $(\mathrm{OR})=3.5,90 \%$ confidence interval $(\mathrm{CI})=1.5-8.1)$, older person feels lonely $(\mathrm{OR}=2.4,90 \% \mathrm{CI}=1.3-4.5)$,

From the *RAND Corporation, Santa Monica, California; Institute of Gerontology and School of Public Health, University of Michigan, Ann Arbor, Michigan; ${ }^{\ddagger}$ Ann Arbor VA Medical Center, Ann Arbor, Michigan; ${ }^{\circledR}$ Department of Medicine and Family Studies, University of Massachusetts Medical Center, Worcester, Massachusetts; IInstitute on Aging at UMass Memorial Health Care, Worcester, Massachusetts; and "Research and Training Institute, Hebrew Rehabilitation Center for Aged, Boston, Massachusetts.

"Deceased.

This paper was awarded an Excellence in Research Award for Students from the Blue Cross/Blue Shield of Michigan Foundation. An earlier version of this paper was presented at the 51st Scientific Meeting of the Gerontological Society of America in Philadelphia, Pennsylvania, November 1998. Dr.

Shugarman's participation in this research began as a doctoral student at the University of Michigan School of Public Health; her work was supported in part by an institutional research training grant from the National Institute on Aging \#T32 AG00114. Drs. Shugarman, Fries, and Morris were also supported in part by the Michigan Public Health Institute \#333300189-18, the Robert Wood Johnson Foundation \#031808, the Older Americans Independence Center \#P60 AG08808, and interRAI.

Address correspondence to Lisa R. Shugarman, RAND Corporation, 1700 Main Street, PO Box 2138, Santa Monica, CA 90407. E-mail: Lisa_Shugarman@rand.org. and older person expresses conflict with family/friends $(\mathrm{OR}=2.3,90 \% \mathrm{CI}=1.2-4.3)$. Home care participants' alcohol abuse, psychiatric illness, lack of ease interacting with others, and short-term memory problems were also significantly associated with the signs of potential elder abuse.

CONCLUSIONS: The results of this study suggest that the signs of potential elder abuse are associated with a diminishing social network and poor social functioning, although some characteristics of the older person's health are contributing factors. Improved understanding of the link between those characteristics and potential abuse will help healthcare providers, case managers, and others identify older people at high risk of abuse. J Am Geriatr Soc 51:24-31, 2003.

Key words: elder abuse; aged; risk factors; family relations; regression analysis

$\mathrm{E}$ der abuse is a serious and growing social problem. In one early study, researchers found that more than three per 100 people aged 65 and older were victims of elder abuse (excluding financial exploitation) in the Boston metropolitan area. ${ }^{1}$ Nationally, 70,942 substantiated new cases were reported to Adult Protective Services (APS) in 1996 (excluding self-neglect cases). ${ }^{2}$ Sentinel reporting agencies (hospitals, public health departments, law enforcement, banks, and elder-care providers) reported an additional 378,982 cases of abuse in fulfilling their obligation to report the suspicion of abuse to APS. ${ }^{2}$ Studies in other countries have found similar rates, indicating this is not just a U.S. phenomenon. ${ }^{3-5}$

Most states now have laws regarding the abuse of older people that include mandatory reporting and prescriptions for treatment of the abusers within the criminal justice system. ${ }^{6}$ Healthcare providers now recognize elder abuse as a real and serious problem. Nevertheless, there is a clear need for more provider education and outreach to train providers to recognize the signs of abuse and neglect of older people. ${ }^{7}$ The current study provides healthcare practitioners in a variety of settings with a list of risk factors that may be useful in recognizing the signs of poten- 
tial elder abuse and the need for further investigation. In this study, potential elder abuse, rather than reported or corroborated elder abuse, is referred to, because the research could not substantiate claims or suspicions of abuse.

Elder abuse is a complicated problem, encompassing physical abuse/neglect, psychological abuse, and financial abuse. ${ }^{1,3,8-15}$ Although various theories have been proposed to explain elder abuse, ${ }^{16-19}$ a single theory may not be adequate to describe such a multifaceted phenomenon. ${ }^{20}$ Some researchers suggest that the increasing frailty and cognitive decline of the older person induces stress in the caregiver, leading to abuse, or that a diminishing social network for both caregiver and older person increase the likelihood of abuse. ${ }^{10,12}$ In addition, provocative or aggressive behavior on the part of older people, such as those with dementia, may trigger an aggressive response on the part of the caregiver. ${ }^{21}$ Others propose that the characteristics of the abuser (e.g., alcohol abuse, mental health or behavioral problems, financial or other dependency on the older person) may be more predictive of elder abuse than the characteristics of the victim. ${ }^{14,18}$ With difficulty in obtaining information from abusers, most research has focused on the victim, who may show outward signs of abuse and is more likely to come into contact with medical and social service personnel.

Identifying a set of risk factors associated with potential elder abuse may allow clinicians and social service providers to intervene at an early stage and stop abuse from continuing, but there is no consensus on a list of risk factors for elder abuse, likely due to differences in research designs, samples, and measures of abuse. ${ }^{1,22}$ Data employed in elder abuse studies come from a variety of sources, including interviews $s^{3,23}$ and public reports to APS or other social service organizations. ${ }^{24}$ The unit of analysis in studying elder abuse has been the victim, ${ }^{1}$ caregiver, ${ }^{16,17}$ family, ${ }^{23}$ and social worker. ${ }^{15}$

This study examines the association between characteristics of community-based older people and a constructed measure of potential elder abuse. The population being studied is one that has regular contact with the healthcare system through publicly funded communitybased long-term care programs in Michigan and is well suited for intervention in abusive situations. Improved understanding of the link between those characteristics and abuse will help healthcare providers, case managers, and others to identify and perhaps prevent abuse.

\section{METHODS}

\section{Data}

Data for this study came from two programs operated by the State of Michigan that were designed to expand the availability of home and community-based services (HCBS) to older and disabled people: the Care Management (CM) Program and the Medicaid Home and Community-Based Services Waiver (the Waiver). Michigan has been operating the CM program since 1983. The Health Care Financing Administration (now Center for Medicare and Medicaid Services) approved the Waiver for operation in 1992 in 14 regions of the state for a 3-year period and in $1998 \mathrm{ex}-$ tended it and expanded it statewide. The population served by the Waiver and CM programs is primarily older $(\geq 60)$ although the Waiver program also serves younger disabled populations. Although both programs use the same functional eligibility criteria, the Waiver program also requires that participants meet the expanded financial eligibility criteria for Medicaid-funded nursing home care. Financially eligible groups include those currently receiving Supplemental Security Income (SSI) or those with income at or below $300 \%$ of the SSI level. The data used in this study were collected to develop a screening instrument to determine eligibility for these programs.

Nurse/social worker case managers working with the home care programs collected data using the Minimum Data Set for Home Care (MDS-HC) during usual assessment practices. These case managers have significant clinical experience working with older people in the community and received intensive training in the use of the MDS-HC before the start of this study.

The MDS-HC is a multidimensional assessment instrument designed to be the community analog to the nationally mandated MDS for nursing homes. (See Morris et al. ${ }^{25}$ for a complete description of the development and reliability testing, and Morris et al. ${ }^{26}$ for information on scoring of individual items.) The MDS-HC uses all possible sources of information (e.g., the client, caregivers, direct observation, medical records) to determine the most appropriate response to each assessment item. All data used in this study were collected during the same assessment visit to the home care participant.

The study sample represents all those residing in the community at baseline who sought long-term care services through the Waiver or CM programs between November 1996 and October 1997. The total sample included 895 older and younger disabled individuals. For the current study, those aged 60 and older residing in the community who reported having at least one informal caregiver present (regardless of living arrangements) were selected $(\mathrm{N}=701)$.

\section{Outcome Variable}

Elder abuse is, by its nature, a hidden offense. Most studies of elder abuse previously cited relied on self-reported cases of abuse ${ }^{1,3,18,23,27}$ or reported (and sometimes corroborated) incidents of abuse. 11,22,28,29 These approaches may underreport the actual incidence of abuse. Older persons may not report abuse because they do not perceive it to be a problem, fear retaliation for reporting it, or feel that the abuse is the result of their own failure by being sick or dependent. ${ }^{12,30}$ Additionally, abuse may be considered a family problem, and thus interference by outsiders would be considered inappropriate.

In this study, the outcome variable measures potential elder abuse rather than reported or corroborated cases of abuse. Physical and emotional abuse and neglect are included in the definition of potential elder abuse. The identification of potential elder abuse relies on assessment by a third party, based on a targeted set of MDS-HC items, in cases potentially not reported to APS or acknowledged by the victim or abuser. Because the largest proportion of abuse and neglect reported to state agencies comes from healthcare providers $(22.5 \%$; followed by family members, $16.3 \%^{24}$ ), third-party observation as described here can be a powerful tool for identifying older people who are or are at risk of being abused.

The MDS-HC incorporates a series of markers that clinicians can use to summarize and support their concerns 
regarding potential abuse. Following a home visit, case managers were asked to synthesize clients' potential abuse status in five functional areas. More specifically, potential elder abuse was deemed present when any of the following were identified: (1) older person is fearful of a family member or caregiver; (2) unusually poor hygiene; (3) unexplained injuries, broken bones, or burns; (4) older person appears neglected or mistreated; and (5) signs of physical restraint (e.g., limbs restrained, bed rails used, or constrained to a chair when sitting). The first of these measures was based on communication with and observation of the client, whereas the remaining measures were based on the case manager's clinical experience in consultation with the client and family members (where possible). Measures of financial abuse were not available. The wording on the elder abuse items in the instrument draws from the literature on abuse, and the items available in the instrument are reliable. Although these five measures of potential abuse were not specifically validated, they are accepted manifestations of abuse according to the protocols for investigation by APS agencies acting within the regulations of state laws for investigation of abuse, neglect, and exploitation.

The measures of potential abuse described above might identify not only abuse by others but also self-neglect or self-abuse, which is an equally important issue but which requires a different set of responses than does abuse perpetrated by others. Any abuse reported to APS will trigger an assessment and intervention by the agency. If abuse or neglect perpetrated by others is substantiated, the criminal justice system generally intervenes. The abused older person may or may not be referred to community organizations for additional support and services. In cases of selfneglect or abuse, APS will respond and often will elicit support from community organizations to develop an intervention that will increase the care an individual receives in the home or make recommendations for institutional care in cases where individuals' cognitive impairments make it unsafe for them to remain in the community. Given that the population being studied is already in contact with health and social service professionals, this study focused, to the extent possible, on identifying cases of abuse perpetrated by others. The study attempted to limit the potential confounding factor of self-neglect or abuse by excluding from the study sample those clients who did not report receiving assistance from at least one informal caregiver (e.g., spouse, child, other relative, or friend). Although it is possible that this measure may still encompass self-neglect and abuse, if informal caregivers are present and involved with the older person's care, they are ultimately responsible for the older person and exclude cases of self-neglect or abuse.

\section{Predictor Variables}

As noted earlier, differences in methodology have made it difficult to identify a consistent set of characteristics associated with elder abuse. This study used the following.

Demographic variables: Some studies variously suggest that abuse is associated with female sex, ${ }^{2}$ older age, ${ }^{1,22,29}$ being married, ${ }^{1,3}$ socioeconomic status (e.g., educational attainment or income level), ${ }^{22,29}$ and nonwhite racial background. ${ }^{11}$ The associations between po- tential abuse and female gender, marital status, advanced age $(\geq 75)$, and educational attainment (<eighth-grade education) were tested for. Income and race/ethnicity variables were not available in the data set used for this study.

Cognition/Psychological Conditions: Previous studies have indicated that elder abuse is associated with impaired cognition ${ }^{11}$ and depression. ${ }^{3,31}$ The analyses included a measure of moderate to severe cognitive impairment based on the Cognitive Performance Scale (CPS), a seven-level variable constructed from the MDS-HC, which is highly predictive of the MiniMental State Examination. The development and validation of the CPS can be found elsewhere. ${ }^{32,33}$ We also considered an additional measure of cognitive status-having short-term memory problemsand signs of depression or anxiety (any of six MDS$\mathrm{HC}$ measures of mood in the week before the assessment: feeling sad, persistent anger with self/others, repetitive anxious complaints/concerns, sad/pained/ worried facial expressions, recurrent crying/tearfulness, or withdrawal from activities of interest).

Medical Conditions/Diagnoses: Stroke $^{23}$ and dementia ${ }^{27,31}$ have been associated with elder abuse. Measures reflecting active (i.e., affecting current care) diagnoses of stroke, Alzheimer's disease, dementia other than Alzheimer's disease, and any psychiatric illness were included.

Physical Functioning: Activities of daily living (ADL) impairments and general poor health have been cited as risk factors for elder abuse. ${ }^{1,3,11,14,22}$ ADL measures for hygiene, dressing, toileting, locomotion, transferring, bed mobility, and eating were included. Each measure compares those totally dependent with those who are independent or require supervision or limited or extensive assistance. In addition, measures of bladder incontinence (occasionally to always incontinent) and bowel incontinence (frequently or totally incontinent) were included.

Behavioral Problems: Older people who exhibit abusive or provocative behavior ${ }^{14,23}$ or who abuse alcohol ${ }^{14,23,28}$ may be at risk for abuse. Four measures of provocative or abusive behavior exhibited in the prior 7 days by the older person were included: physically abusive, verbally abusive, socially inappropriate behavior, and active resistance of care. Alcohol abuse was measured as the older person feels the need or has been told by others to cut down on drinking or the older person has to have a drink first thing in the morning or has been in any sort of trouble because of drinking.

Social Functioning/Support: Various aspects of the social support system and social functioning have been associated with elder abuse. These include residing with others, ${ }^{1,11,27}$ being socially isolated, ${ }^{14}$ having conflicts with family members or friends, ${ }^{14}$ or having a brittle support system. ${ }^{1,3,14,22,23}$ Included in the analyses were variables that indicate that the older person is not at ease interacting with others, openly expresses conflict or anger with family/friends, is socially isolated (older person says he/she feels lonely), and has a brittle support system (two or more of the following indicators: a primary caregiver reports that he/she is unable to 
identify or provide care should the need arise; absence of a commitment by the caregiver to continue current activities; a primary caregiver is not satisfied with support received from family and friends; or the primary caregiver expresses feelings of anger or depression).

\section{Analysis Plan}

A cross-sectional study design was used to understand the association between home care participant characteristics and the composite measure of potential abuse. Two separate analytical steps were taken to understand better the association of individual characteristics and potential elder abuse, the dependent variable. All variables in the model are indicator variables, with " 1 " associated with the presence of that factor identified in the literature as associated with abuse. Bivariate associations were measured using the chi-square statistic. Then each predictor variable significantly associated with the dependent variable in the bivariate case $(P<.10)$ was included in a logistic regression model where the measure of potential abuse was the outcome. A reduced logistic regression was estimated with only those variables found to be statistically significant in the original logistic regression. Odds ratios (ORs) and $90 \%$ confidence intervals (CIs) for each predictor variable were obtained from the regression models. Wald chisquare statistics and $P$-values were used to evaluate the significance of individual model parameters, and the Hosmer-Lemeshow goodness-of-fit chi-square test was employed to assess the overall fit of logistic models. ${ }^{34}$

All analyses were computed using SAS, version 6.11 (SAS Institute, Inc., Cary, NC). To preserve the sample size in the logistic regressions, the age- and sex-adjusted mean values for the variables where there were missing cases were imputed. Of the 30 variables considered in this study, nine had at least one missing value. The variable with the most missing values (19 cases, or $2.7 \%$ ) was educational attainment.

\section{RESULTS}

Table 1 presents the frequency of the outcome variable and key demographic characteristics of the sample. Thirty-

Table 1. Demographic Characteristics and Distribution of Outcome Measure $(\mathrm{N}=701)$

\begin{tabular}{lc}
\hline \multicolumn{1}{c}{ Variable } & Value \\
\hline Age, mean \pm SD & $77.8 \pm 8.5$ \\
Female, $\%$ & 71.9 \\
Married, \% & 36.7 \\
Less than 8th grade education, \% & 30.4 \\
Potential cases of abuse, \% & $4.7(n=33)$ \\
For each sign of potential abuse, ${ }^{\dagger}$ & \\
Fearful of family & $24.2(n=8)$ \\
Poor hygiene & $39.4(n=13)$ \\
Unexplained injuries & $6.1(n=2)$ \\
Neglected or mistreated & $21.2(n=7)$ \\
Physically restrained & $15.2(n=5)$ \\
\hline
\end{tabular}

${ }^{\dagger}$ Total exceeds $100 \%$ because some subjects exhibited more than one measure of abuse.

$\mathrm{SD}=$ standard deviation. three of the 701 older people in the sample $(4.7 \%)$ had at least one of the signs associated with potential elder abuse. This proportion is slightly higher than that found in previous studies that exclude financial exploitation. Of the cases of abuse, $13(39.4 \%)$ had poor hygiene, eight $(24.4 \%)$ showed signs of being fearful of a family member, seven $(21.1 \%)$ appeared neglected or mistreated, five $(15.2 \%)$ were physically restrained, and two $(6.1 \%)$ had unexplained injuries. All but two individuals who were identified as showing signs of abuse "triggered" on a single abuse factors; the others triggered on two.

The average age of the sample was 77.8 (range $=60$ 99). Women constituted the majority of the sample $(71.9 \%)$, and slightly more than one-third $(36.7 \%)$ were married. Approximately $30 \%$ of the sample had less than an eighth grade education.

\section{Bivariate Analyses}

Table 2 presents the results of the bivariate analyses of potential elder abuse and the prevalence of each characteristic or condition in those for whom signs of potential elder abuse were present or absent. For example, 22 (66.7\%) older people identified as potential abuse victims were of advanced age $(\geq 75)$, and $438(65.6 \%)$ of all others were also aged 75 and older; this measure was not a significant predictor of abuse.

None of the demographic variables (age, sex, marital status, and education) were found to be significant in the bivariate analyses. Of the measures of cognition and clinical diagnoses, only psychiatric illness was significantly associated with abuse. Four measures of physical functioning were significant in the bivariate case: hygiene, dressing, bladder incontinence, and bowel incontinence.

All of the behavioral problem variables were significantly associated with potential elder abuse. Cases in which the older person was physically abusive or actively resisted care demonstrated the strongest association with potential abuse. In cases where the older person abused alcohol, there was a significantly higher prevalence of potential elder abuse. Finally, all social functioning and support variables were significantly associated with potential elder abuse; older people who were not at ease interacting with others, who openly expressed conflict, or indicated that they felt lonely or had a brittle support system were all more likely to show signs of potential elder abuse.

\section{Logistic Regression}

Table 3 presents the ORs and the $90 \%$ CIs about the parameter estimates for each of two logistic regression models in which the association between home care participant characteristics and the measure of potential abuse was studied. (Although not significant in the bivariate case, sex was retained as a control variable in the multivariate analyses).

\section{Full Model}

The full model includes all the predictor variables found to be significant in the bivariate case.

Cognitive Patterns: Having a short-term memory problem was strongly associated with the measure of potential elder abuse $(\mathrm{OR}=2.66 ; 90 \% \mathrm{CI}=1.28-5.34)$, 
Table 2. Variable Frequencies and Bivariate Analysis Results

\begin{tabular}{|c|c|c|c|}
\hline \multirow[b]{2}{*}{ Variable } & \multicolumn{2}{|c|}{ Signs of Potential Abuse } & \multirow[b]{2}{*}{$P$-value ${ }^{\mathrm{a}}$} \\
\hline & $\begin{array}{c}\text { Present } \\
n=33(\%)\end{array}$ & $\begin{array}{c}\text { Absent } \\
\mathrm{n}=668(\%)\end{array}$ & \\
\hline \multicolumn{4}{|l|}{ Demographics } \\
\hline Age $>75$ & $22(66.7)$ & $438(65.6)$ & \\
\hline Female & $26(78.8)$ & $474(71.6)$ & \\
\hline Education < 8th grade & $11(35.5)$ & $196(30.1)$ & \\
\hline \multicolumn{4}{|l|}{ Cognitive patterns } \\
\hline Short-term memory problem & $23(69.7)$ & $318(47.6)$ & $<.05$ \\
\hline Cognitive performance scale ${ }^{b}$ & $26(78.8)$ & $592(88.6)$ & $<.10$ \\
\hline Depression/anxietyc & $12(36.4)$ & $133(19.9)$ & $<.05$ \\
\hline \multicolumn{4}{|l|}{ Disease diagnoses } \\
\hline \multicolumn{4}{|l|}{ Physical functioning } \\
\hline Hygiene ${ }^{d}$ & $6(18.2)$ & $48(7.2)$ & $<.05$ \\
\hline Dressing $^{d}$ & $6(18.2)$ & $54(8.1)$ & $<.05$ \\
\hline Toileting $^{d}$ & $3(9.1)$ & $46(6.9)$ & \\
\hline Locomotiond $^{d}$ & $3(9.1)$ & $39(5.9)$ & \\
\hline Transferring ${ }^{d}$ & $3(9.1)$ & $34(5.1)$ & \\
\hline Bed mobility ${ }^{d}$ & $0(0.0)$ & $22(3.3)$ & \\
\hline Eating $^{d}$ & $2(6.1)$ & $18(2.7)$ & \\
\hline Bladder incontinence ${ }^{e}$ & $16(48.5)$ & $217(32.5)$ & $<.05$ \\
\hline Bowel incontinence ${ }^{f}$ & $8(25.8)$ & $87(13.0)$ & $<.05$ \\
\hline \multicolumn{4}{|l|}{ Behavioral problems } \\
\hline Indicates feels lonely & $18(56.3)$ & $231(36.1)$ & $<.01$ \\
\hline Brittle support system & $28(84.9)$ & $411(65.3)$ & $<.01$ \\
\hline
\end{tabular}

a Using chi-square test.

${ }^{b}$ Moderate to severe impairment.

$c \geq 1$ selected measures of mood.

dTotal dependence (full performance of activity performed by another).

'Occasional to daily incontinence.

${ }^{\mathrm{f}}$ Frequent to daily incontinence.

gExhibited in the previous 7 days.

but neither cognitive performance nor depression/ anxiety were found to be significant. A potential collinearity problem between the variable measuring short-term memory and the Cognitive Performance Scale (CPS) was identified, but, when these variables were entered separately into the logistic regression, it was still found that a short-term memory problem was significant and the CPS was not significant.

Disease Diagnoses: The only disease diagnosis found to be significant in the bivariate analyses, psychiatric illness, was also significantly associated in the multivariate regression $(\mathrm{OR}=2.48 ; 90 \% \mathrm{CI}=1.18-5.23)$.
Physical Functioning: Measures of physical functioning (hygiene, dressing, bladder incontinence, and bowel incontinence) were not found to be significant in the logistic model.

Behavioral Problems: The only behavioral problem found to be significantly associated with potential elder abuse was alcohol abuse, associated with a 10 times greater prevalence of observed signs of potential elder abuse $(\mathrm{OR}=10.26,90 \% \mathrm{CI}=2.73-38.5)$.

Social Functioning and Support: All four of the social functioning and support variables were significantly associated with the outcome of potential el- 
Table 3. Odds Ratios and Confidence Intervals for Full and Reduced Logistic Regression Models

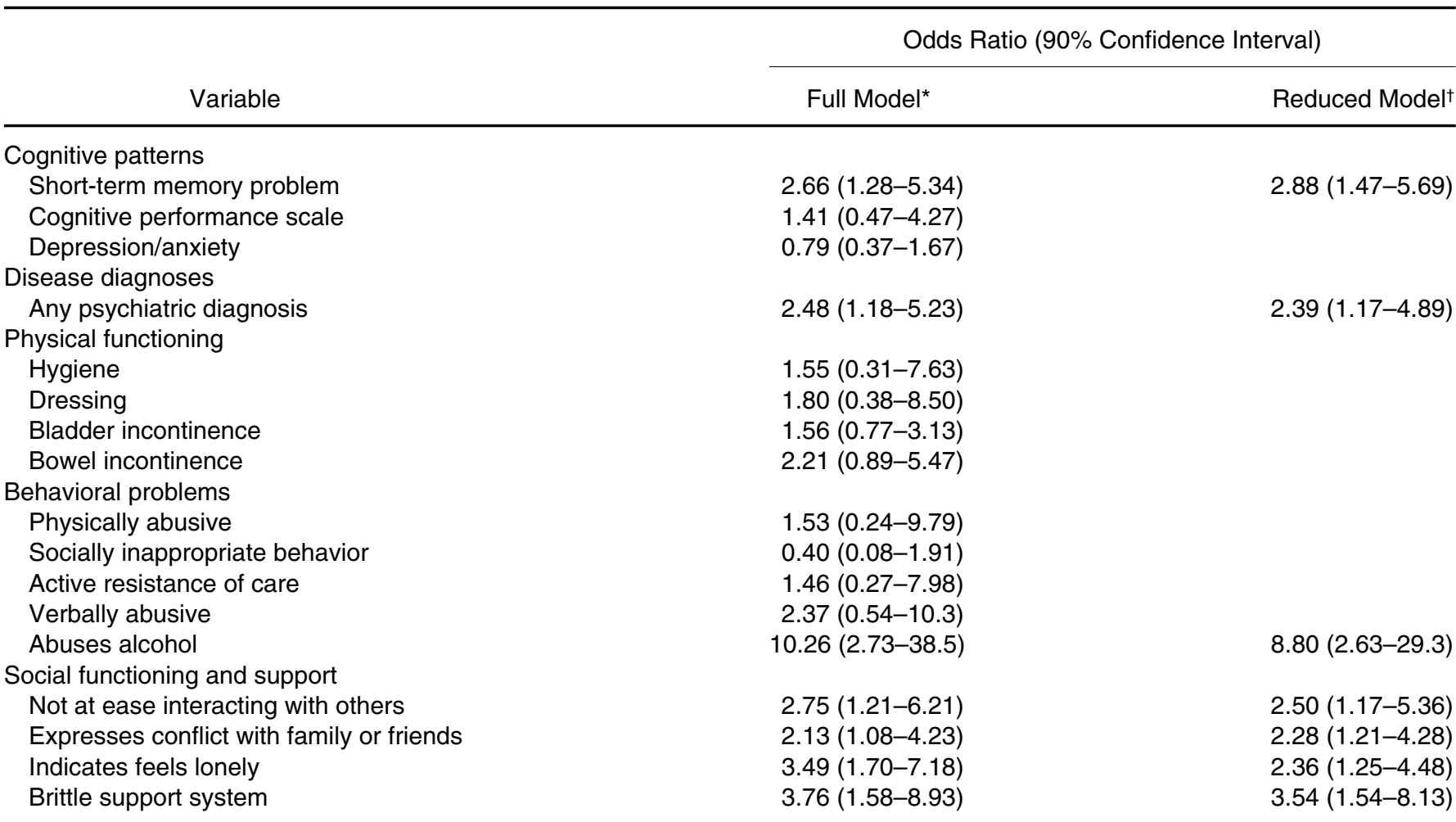

Both multivariate models controlled for gender.

${ }^{\star}$ Full model contains all variables found to be significant in the bivariate analyses. The Hosmer-Lemeshow goodness-of-fit chi-square statistic is $12.26, P=.14$.

tReduced model contains all variables found to be significant in the full model. The Hosmer-Lemeshow goodness-of-fit chi-square statistic is $6.40, P=.60$.

der abuse, with ORs ranging from 2.13 (expresses conflict with family/friends) to 3.76 (brittle support system).

\section{Reduced Model}

The reduced model incorporated only those variables that were significant in the full model, and the results showed that all remained statistically significant. It was more parsimonious and had a better goodness-of-fit; the HosmerLemeshow test suggests poor fit for the full model $\left(\chi^{2}=\right.$ $12.26, P=.14)$, but better fit here $\left(\chi^{2}=6.40, P=.60\right)$.

\section{Identification of High-Risk Clients}

The seven items from the MDS-HC identified as important predictors associated with potential elder abuse can be combined into a simple index that a healthcare professional can use to screen for potential elder abuse. A diagnostic test was conducted to determine the sensitivity and specificity of different cutpoints of the resulting index of potential elder abuse items. Figure 1 illustrates the various decision thresholds along the receiver operating characteristic (ROC) curve. The index of characteristics demonstrated high sensitivity; older people with three or more of these characteristics were correctly identified as having potentially been abused in more than $90 \%$ of the cases. Nevertheless, these characteristics are not specific; almost $60 \%$ of older people with three or more of these characteristics who were not identified as potentially abused were incorrectly classified as being in a potentially abusive environment.

\section{DISCUSSION}

From a clinical point of view, the results of this study show strong associations between potential elder abuse and an older person's short-term memory problem, psychiatric diagnosis, and alcohol abuse. The social functioning and support category of variables (not at ease interacting with others, openly expresses conflict with family and friends, indicates feeling lonely, and has signs of a brittle support system) were, as a group, the most strongly associated with potential elder abuse. No significant association

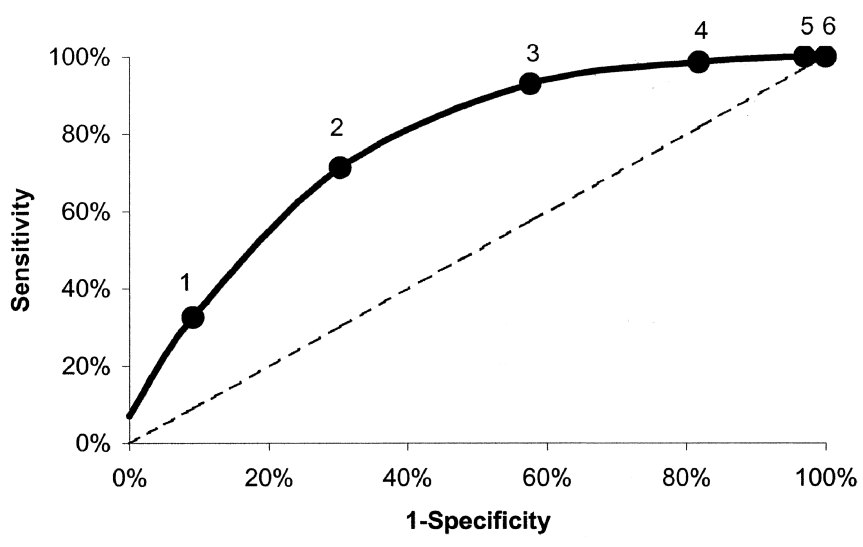

Figure 1. Receiver operating characteristic curve of the sensitivity and specificity of characteristics associated with potential abuse. 
between demographic characteristics and measures of physical functioning of the older person and the observed signs of potential elder abuse was found.

The seven home care participant characteristics identified through the analyses can be used in conjunction with the specific questions regarding physical or emotional abuse and neglect of older people found in the MDS-HC. For example, these characteristics may be incorporated into an improved trigger for which care planning and perhaps APS intervention should be initiated. The characteristics identified demonstrate high sensitivity but relatively low specificity, meaning that those who exhibit signs of potential abuse are likely to have many of the seven characteristics identified in the analyses. However, there are many individuals with those characteristics that may be identified as potentially abused that are not actually living in abusive situations. Of course, it is preferable to maximize both sensitivity and specificity, but, when faced with a trade-off, as in this case, the healthcare professional may want to maintain a more conservative stance.

Based on the findings of diagnostic testing in this study, it is suggested that cases in which individuals "trigger" on three of the seven predictors of potential abuse be followed up with further investigation. As mentioned above, using three items as the cutpoint increases the likelihood of false positives. However, because of the seriousness of the issue, it may be more important to "cast a wider net." In the broader context, these findings both agree and disagree with prior empirical studies. The association between demographic characteristics and abuse is the area of previous research where there has been the most disagreement. Pillemer et al. ${ }^{1}$ found that men were at greater risk of elder abuse, although abuse against women may be more likely to be reported to authorities. In addition, studies relying on reported cases of abuse may overrepresent the nonwhite population and those of lower socioeconomic status because these populations are more likely than others to come in contact with the social welfare system. ${ }^{11}$ Although this study did not have information available on race/ethnicity, no association between education, a proxy for socioeconomic status, and abuse was found. However, because the sample came from a low-income population, there was little variation in socioeconomic status, which may have contributed to the lack of significant findings.

Alcohol abuse by the older person was also associated with potential elder abuse. Previous studies have found that alcohol abuse by caregivers may lead them to abuse the care recipient, ${ }^{14}$ and, in households where one individual abuses alcohol, others are likely to do the same. ${ }^{28}$ Therefore, alcohol abuse by the older person may be predictive of an abusive situation in the home. However, this study did not have information on caregiver alcohol abuse, and, given the relatively small sample of older people who abused alcohol in the sample, caution should be taken in interpreting these results.

Others have theorized that elder abuse may be related to increasing frailty and cognitive decline of the older person, inducing stress in the caregiver, or that a poor social network for older persons and their caregivers may increase the likelihood of abuse. The results of this report suggest that the latter theory is more strongly supported, although some characteristics of the older person's health are contributing factors. This conclusion also helps to explain why the demographic and physical functioning variables were not significantly associated with the signs of potential elder abuse.

Discrepancies between these results and those from previous studies may be due to sampling and methodological differences. The current study focused on a communitybased sample of older persons who had contact with HCBS programs funded by the state or jointly funded by state and federal governments, whereas earlier studies employed samples of the general population, ${ }^{1,3}$ abuse cases reported to state agencies, ${ }^{24}$ or convenience samples. ${ }^{15}$ In addition, the sample was limited to persons who were generally functionally disabled. Physical abuse, for example is more apt to be associated with older people who are independent in ADLs, ${ }^{18}$ but this population is underrepresented in this study. Nevertheless, there is substantial consistency between this study and others in identifying brittle social supports as an important factor in understanding the characteristics associated with potential elder abuse. Such agreement across these studies using varied samples adds strength to the conclusion that older people with poor social supports may be more vulnerable to abuse.

\section{Study Limitations}

The measure of potential elder abuse is based on a thirdparty assessment and synthesis of information collected during an in-person visit with older persons and their families. The clinicians conducting the assessment have identified signs of abuse through a data collection process but present no substantiated evidence of actual abuse. The study comments only on the potential for abuse. However, healthcare providers are only required to be suspicious of abuse to file a report with APS. It is the job of APS personnel to follow up and substantiate a claim of abuse.

The cross-sectional design that was used here allowed only for comment on associations between individual characteristics and potential elder abuse, not for attribution of cause and effect. Further studies will use longitudinal data to study the causal relationships between the important characteristics identified in this study and potential elder abuse over time.

The sample was limited to home care participants with at least one informal caregiver present. It was assumed that, if an informal caregiver were present, any indicators of potential abuse were more likely abuse perpetrated by others rather than self-neglect or abuse. Nevertheless, it is possible that self-neglect/self-abuse rather than abuse perpetrated by another individual may best explain some of the characteristics associated with potential elder abuse. In particular, the variables measuring a short-term memory problem and having a psychiatric diagnosis may be more associated with self-abuse.

\section{CONCLUSION}

This study identified important individual characteristics that healthcare and social service providers can use to identify potential or ongoing abuse of the older people they serve. Given that this study identified characteristics associated with the potential for elder abuse, a more preventive approach may be feasible in addressing the prob- 
lem. Because this sample is drawn from a population that comes into contact with health and social services, they are more likely to have someone to intervene in cases of abuse. Finally, this study suggests that the use of comprehensive screening, such as that accomplished by the MDS-HC, will enable clinicians and social service providers to identify and assist older people and families at risk of abuse.

\section{ACKNOWLEDGMENTS}

The authors would like to thank Mary James of the Michigan Department of Community Health and Bill Trythall for their assistance and thoughtful contributions to the development of this research and resulting paper.

\section{REFERENCES}

1. Pillemer K, Finkelhor D. The prevalence of elder abuse: A random sample survey. Gerontologist 1988;28:51-57.

2. National Center on Elder Abuse. National Elder Abuse Incidence Study. Washington, DC: American Public Human Services Association, 1998.

3. Podnieks E. National survey on abuse of the elderly in Canada. J Elder Abuse Neglect 1992;4:5-58.

4. Ogg J. Researching elder abuse in Britain. J Elder Abuse Neglect 1993;5:3754.

5. Kivelä S, Köngäs-Saviaro $\mathrm{P}$, Kesti $\mathrm{E}$ et al. Abuse in old age: Epidemiological data from Finland. J Elder Abuse Neglect 1992;4:1-18.

6. Macolini RM. Elder abuse policy. Considerations in research and legislation. Behav Sci Law 1995;13:349-363.

7. Marshall CE, Benton D, Brazier JM. Elder abuse. Using clinical tools to identify clues of mistreatment. Geriatrics 2000;55:47-50,53.

8. Benton D, Marshall C. Elder abuse. Clin Geriatr Med 1991;7:831-845.

9. Bloom JS, Ansell P, Bloom MN. Detecting elder abuse: A guide for physicians. Geriatrics 1989;44:40-56.

10. Lachs MS, Fulmer T. Recognizing elder abuse and neglect. Clin Geriatr Med 1993;9:665-675.

11. Lachs MS, Williams $\mathrm{C}, \mathrm{O}$ 'Brien $\mathrm{S}$ et al. Risk factors for reported elder abuse and neglect: A nine-year observational cohort study. Gerontologist 1997;37: 469-474.

12. Lay T. The flourishing problem of elder abuse in our society. AACN Clin Issues Crit Care Nurs 1994;5:507-515.

13. Vida S. An update on elder abuse and neglect. Can J Psychiatry 1994;39: S34-S40.

14. Reis M, Nahmiash D. Validation of the Indicators of Abuse (IOA) screen. Gerontologist 1998;38:471-480.
15. Hickey T, Douglass RL. Neglect and abuse of older family members: Professionals' perspectives and case experiences. Gerontologist 1981;21:171-176.

16. Phillips LR. Abuse and neglect of the frail elderly at home: An exploration of theoretical relationships. J Adv Nurs 1983;8:379-392.

17. Steinmetz SK. Duty Bound. Elder Abuse and Family Care. Newbury Park, CA: Sage, 1988.

18. Pillemer K, Finkelhor D. Causes of elder abuse: Caregiver stress versus problem relatives. Am J Orthopsychiatry 1989;59:179-187.

19. Aitken L, Griffin G. Gender Issues in Elder Abuse. London: Sage, 1996.

20. Stein KF. Elder Abuse and Neglect: A Research Agenda. Washington, DC: National Aging Resource Center on Elder Abuse, 1991.

21. Pillemer K, Suitor JJ. Violence and violent feelings: What causes them among family caregivers? J Gerontol 1992;47:S165-S172.

22. Lachs M, Berkman L, Fulmer T et al. A prospective community-based pilot study of risk factors for the investigation of elder mistreatment. J Am Geriatr Soc 1994;42:169-173.

23. Homer AC, Gilleard C. Abuse of elderly people by their carers. BMJ 1990 ; 301:1359-1362.

24. National Center on Elder Abuse. Elder Abuse in Domestic Settings. Information Series. Washington, DC: American Public Human Services Association, 1997.

25. Morris JN, Fries BE, Steel K et al. Comprehensive clinical assessment in community setting: Applicability of the MDS-HC. J Am Geriatr Soc 1997;45: 1017-1024.

26. Morris JN, Fries BE, Bernabei R et al. RAI-Home Care (RAI-HC) ${ }^{\circ}$ Assessment Manual For Version 2.0. Marblehead, MA: Opus Communications, 2001.

27. Paveza GJ, Cohen D, Eisdorfer C et al. Severe family violence and Alzheimer's disease: Prevalence and risk factors. Gerontologist 1992;32:493497.

28. Hwalek MA, Neale AV, Goodrich CS et al. The association of elder abuse and substance abuse in the Illinois elder abuse system. Gerontologist 1996; 36:694-700.

29. Lachs MS, Williams C, O'Brien S et al. Older adults: An 11-year longitudinal study of adult protective service use. Arch Intern Med 1996;156:449-453.

30. Kosberg JI. Preventing elder abuse: Identification of high risk factors prior to placement decisions. Gerontologist 1988;28:43-50.

31. Dyer CB, Pavlik VN, Murphy KP et al. The high prevalence of depression and dementia in elder abuse or neglect. J Am Geriatr Soc 2000;48:205208.

32. Hartmaier SL, Sloane PD, Guess SA et al. Validation of the Minimum Data Set Cognitive Performance Scale: Agreement with the Mini-Mental State Examination. J Gerontol A Biol Sci Med Sci 1995;50A:M128-M133.

33. Morris JN, Fries BE, Mehr DR et al. MDS Cognitive Performance Scale. J Gerontol A Biol Sci Med Sci 1994;49A:M174-M182.

34. Hosmer DWJ, Lemeshow S. Applied Logistic Regression. New York, NY: Wiley, 1989. 